\title{
Algorithm to obtain inverse kinematics matrix from the 3D curve and to apply to glue shoe sole
}

- Ha Le Nhu Ngoc Thanh

- Luu Thanh Tung

- Nguyen Tan Tien

Ho Chi Minh city University of Technology, VNU-HCM

(Manuscript Received on October $7^{\text {th }}$, 2014; Manuscript Revised December $14^{\text {th }}$, 2014)

\begin{abstract}
:
Nowadays, manipulator is widely used in industrial applications. The trajectories of manipulator are more and more complicated. In order to do good tracking performance, the end effector position and orientation have to be determined. This paper describes a method to determine position and orientation of manipulator's end effector base on a reference path. This method will be applied for manipulator 6 DOF to glue shoe sole. Firstly, assume the reference path is arbitrary curve, the path was then discrete to become multi-point.

Secondly, the roll - pitch - yaw vectors of the end effector will be determined at each point. Finally, Euler angles and interpolation method in $3 D$ space will be applied to determine inverse kinematics matrix of manipulator for each point on the reference path. In addition, this paper also gives an example of reference path of shoe sole to apply the presented method. To verify the tracking performance of manipulator and reference path, a PID controller was designed for simulation. The result of simulation proved the correction of the algorithm.
\end{abstract}

Keywords: Inverse kinematics matrix, 3D curve, glue shoe sole

\section{INTRODUCTION}

Most of manipulators were controlled by using teach pendant. Controller of manipulator is integrated available programs. Users only use teach pendant to control manipulator for their application. Mostly, users can not rewrite or edit the program of manipulator's controller. After the teaching is completed, the manipulator will repeat the process taught. So, it is very difficult for manipulator closely tracking a reference path. The errors of tracking process entirely depend on the skill and experience of the users. Therefore, teach pendant is used to control manipulator when the accuracy of tracking performance is not interested.

However, in the practical applications, the 
reference path is complex curve without precise mathematical equation. In addition, high accuracy of tracking performance is required. Furthermore, the end effector's orientation continuously changes during tracking process. So, it is a cause cannot use teach pendant to control manipulator's trajectory. To solve this problem, the automatic controller must be applied. But, this method is not easy to work, the biggest problem is how to get inverse kinematics matrix of manipulator from the reference path. It means that the user must calculate the joint variables of manipulator. These joint variables must satisfy both position and orientation of manipulator during tracking process.

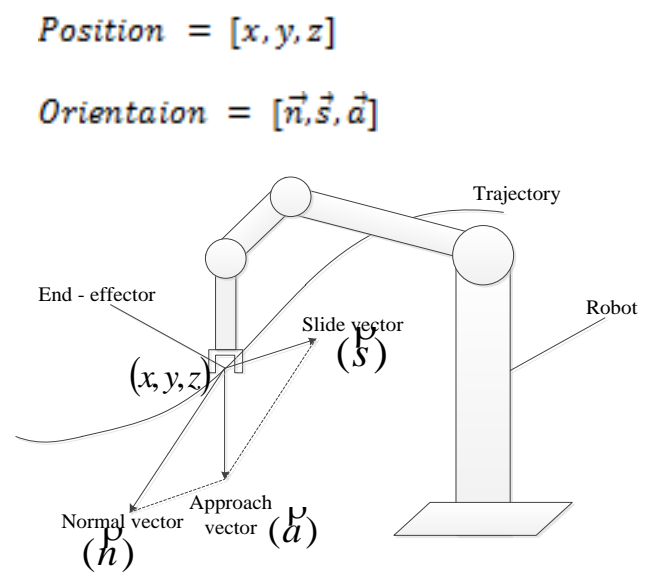

Figure 1. Tracking trajectory on the manipulator

To solve this problem, there are some relative researches having recently been developed. Raşit Köker et al. [1] presented the neural network to find inverse kinematics solution of manipulator, this method generated many initial and final points in the work volume of the robotic manipulator by using cubic trajectory planning. Then, all of the angles according to the real-world coordinates $(x, y, z)$ are recorded in a file named as training set of neural network. Lastly, they used a designed neural network to solve the inverse kinematics problem. Wang, C.C.T et al.[2] proposed a new method for computing numerical solutions to the inverse kinematics problem for robotic manipulator. The method is based on a combination of two nonlinear programming techniques and forward recursion formulas. Thompson, Stuart E. et al. [3] described a new procedure for constructing robot trajectories by using B-splines. The motion of the robot, as specified by a time sequence of position and orientation knots of the end effector, B-splines are then used to fit these sequences for each joint. A trajectory constructed by this method has the property that a local modification can be made quickly and easily without re-computing the entire trajectory. Chi-Haur $\mathrm{Wu}$ et al.[4] presented a novel geometric method for the planning and controlling the orientation of a robot's end effector as moves along a prescribed translational path. To eliminate the influence of geometric changes to the path and to be able to predict the orientation, the proposed method plans rotational paths with respect to a natural local coordinate frame formed by three unit vectors, namely the tangent, normal, and binormal vectors, defined by the geometry of the path. J. Angeles et al.[5] proposed a method to find trajectory planning of robot motions for continuous path. Method resorted to the intrinsic properties of the path traced by point of the end effector. It is shown that, by referring the orientation of the end effector to a unique orthogonal frame defined at every point of the aforementioned path, a systematic procedure for trajectory planning in configuration space is derived. Rafael Renan Pacheco et al.[6] proposed a method to identify and analyze a technique to be used in a $3 \mathrm{D}$ virtual robotic simulator that executes smooth and continuous

\section{Trang 6}


movement. Thomas Horsch et al.[7] described an algorithm for interpolation of position by rational spline motion, The whole spline scheme possesses some special features which make it a suitable tool for the control of industrial robots. S.D Voliotics et al.[8] presented an algorithm of trajectory planning for wrist partitioned robotic manipulator. The path is generated as a sequence of elementary motions. Each new position is defined as a function of the previous one. After having derived a position, the orientation is planned using an optimal process.

The mentioned papers either give the solution for general inverse kinematics of manipulator or interpolate to get the position of manipulator's working path. However, they do not clearly mention how to take orientation of manipulator when the orientation continuously changes during tracking process.

This paper proposes a method to obtain inverse kinematics matrix from 3D curve based on Euler angles and interpolation method. This paper clearly solved inverse kinematics problem and to show a method to take the orientation of manipulator when the orientation continuously changes during tracking process. This method will be applied for manipulator 6 DOF to glue shoe sole.

\section{ALGORITHM}

A block diagram of the proposed algorithm is shown in Fig.2

\begin{tabular}{|c|c|c|c|}
\hline Traiectory & & Find the Position & \\
\hline 11ajectury & $\rightarrow \begin{array}{l}\text { Diviue } \\
\text { triectory to }\end{array}$ & and Orientation & Transformation \\
\hline advance) & multipoint & of end effector at & matrix \\
\hline & & each & \\
\hline
\end{tabular}

Figure 2. A block diagram of the proposed algorithm

The trajectory (reference path) is divided into multipoint. Manipulator tracks the trajectory, it goes through these points. The position and orientation of the end effector can be found at each point. Thus, the inverse kinematics matrix can be obtained base on Euler angles.

Let $P_{i},(i=1 \div n)$ (n is number of points) are multipoint of reference path,

The position of each point:

$P_{\mathrm{i}}=\left[\begin{array}{l}P_{\mathrm{ix}} \\ P_{\mathrm{i} y} \\ P_{\mathrm{iz}}\end{array}\right]$

Assume, the orientation which robot's end effector must track at $P_{\mathrm{i}} ;\left[\vec{n}_{\mathrm{i}}, \vec{o}_{\mathrm{i}}, \vec{a}_{\mathrm{i}}\right]$. Where $\vec{a}$ vector is the approach vector, $\vec{o}$ is tangent vector at each point on curve (This curve is interpolated from three consecutive points), $\vec{n}$ is remainder vector, which is calculated by cross from $\vec{a}$ and $\vec{o}$ (Fig.3).

The orientation of end effector:

$$
\left[\vec{n}_{i}, \vec{o}_{i j}, \vec{a}_{i}\right]=\left[\begin{array}{lll}
n_{i x} & o_{i x} & a_{i x} \\
n_{i y} & o_{i y} & a_{i y} \\
n_{i z} & o_{i z} & a_{i z}
\end{array}\right]
$$

With three consecutive points $P_{i}, P_{i+1}, P_{i+2}$ of reference path, to create a plane with normal vector:

$\vec{a}_{\mathrm{i}}=\vec{a}_{\mathrm{i}+1}=\vec{a}_{\mathrm{i}+2}=\left[\overrightarrow{P_{\mathrm{i}} P_{\mathrm{I}+1}}, \overrightarrow{P_{\mathrm{I}+1} P_{\mathrm{I}+2}}\right]$

where, $\vec{a}_{i+1}, \vec{a}_{i+2}$ are normal vectors at points $P_{\mathrm{i}+1}, P_{\mathrm{i}+2}$ respectively

With three consecutive points $P_{\mathrm{i}}, P_{\mathrm{i}+1}, P_{\mathrm{i}+2}$ of reference path, to interpolate a curve (Quadratic Splines):

$$
\begin{aligned}
& Q(u)=c_{0}+c_{1} u+c_{2} u^{2}=\sum_{k=0}^{2} c_{k} u^{k} \\
& (0 \leq k \leq 2) \\
& \text { where, } \quad c_{k} \quad \text { is a column vector } \\
& c_{k}=\left[c_{k x}, c_{k y} c_{k z}\right]^{T},
\end{aligned}
$$


$Q(u)$ is a vector, $0 \leq u \leq 1$,

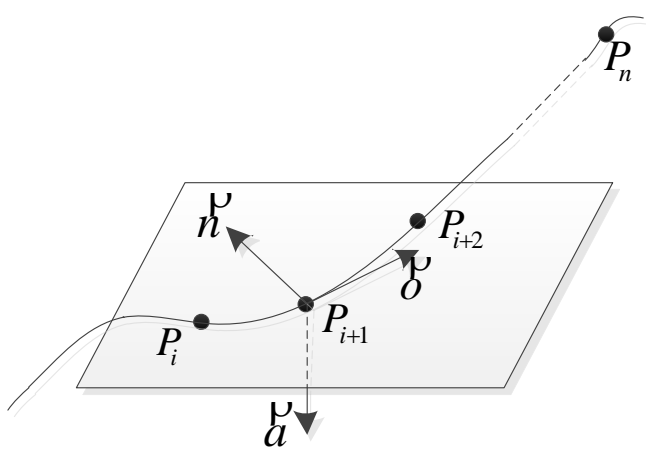

Figure 3. Plane through three consecutive points

$Q(u)$ is specified by three coefficients and can be solved as follows,

At point $P_{1}, u=0$

$P_{\mathrm{i}}=Q(0)=c_{0}+c_{1} 0+c_{2} 0^{2}$

At point $P_{i+1}, u=1 / 2$

$P_{i+1}=Q\left(\frac{1}{2}\right)=c_{0}+c_{1}\left(\frac{1}{2}\right)+c_{2}\left(\frac{1}{2}\right)^{2}$

At point $P_{\mathrm{i}+2}, u=1$

$P_{i+2}=Q(1)=c_{0}+c_{1} 1+c_{2} 1^{2}$

Therefore,

$\left[\begin{array}{l}P_{i} \\ P_{i+1} \\ P_{i+2}\end{array}\right]=\left[\begin{array}{ccc}1 & 0 & 0 \\ 0 & \frac{1}{2} & \left(\frac{1}{2}\right)^{2} \\ 1 & 1 & 1\end{array}\right]\left[\begin{array}{l}c_{0} \\ c_{1} \\ c_{2}\end{array}\right]$

Solve the above equation to obtain

$\left\{\begin{array}{l}c_{0}=P_{i} \\ c_{1}=P_{i}+4 P_{i+1}-P_{i+2} \\ c_{2}=-2 P_{i}-4 P_{i+1}+2 P_{i+2}\end{array}\right.$

where, $c_{0}, c_{1}, c_{2}$ are coefficients of interpolated curve through three consecutive points $P_{\mathrm{i},}, P_{\mathrm{i}+1}, P_{\mathrm{i}+2}$. $\vec{o}$ is a tangent vector, it is specified by tangential equation (Fig.3)

$$
\vec{o}=\phi(u)=c_{1}+2 c_{2} u
$$

Substitute Eq.(2) into Eq.(3), keep in mind $0 \leq u \leq 1$, Eq. (3) can be written as follows:

$$
\begin{aligned}
\vec{o}=P_{\mathrm{i}}+ & 4 P_{\mathrm{i}+1}-P_{\mathrm{i}+2} \\
& +2\left(-2 P_{\mathrm{i}}-4 P_{\mathrm{i}+1}+2 P_{\mathrm{i}+2}\right) u
\end{aligned}
$$

At point $P_{\mathrm{i}}, u=0$

$\vec{o}_{\mathrm{i}}=P_{\mathrm{i}}+4 P_{\mathrm{i}+1}-P_{\mathrm{i}+2}$

At point $P_{\mathrm{i}+1}, u=1 / 2$

$\vec{o}_{\mathrm{i}+1}=P_{\mathrm{i}}+4 P_{\mathrm{i}+1}-P_{\mathrm{i}+2}$

$$
+2\left(-2 P_{i}-4 P_{i+1}+2 P_{i+2}\right) \frac{1}{2}
$$

At point $P_{i+2}, u=1$

$\vec{o}_{i+2}=P_{i}+4 P_{i+1}-P_{i+2}$

$$
+2\left(-2 P_{i}-4 P_{i+1}+2 P_{i+2}\right) 1
$$

From Eqs.(1),(5),(6),(7), the remainder vector $\vec{n}$ will be obtained as follows,

$$
\begin{aligned}
& \vec{n}_{i}=\left[\vec{a}_{i}, \vec{o}_{i}\right] \\
& \vec{n}_{i+1}=\left[\vec{a}_{i+1}, \vec{o}_{i+1}\right] \\
& \vec{n}_{i+2}=\left[\vec{a}_{i+2}, \vec{o}_{i+2}\right]
\end{aligned}
$$

Thus, at each point on the interpolated curve, the position $(x, y, z)$ and the orientation $[\vec{n}, \vec{o}, \vec{a}]$ can be obtained. These are also position and orientation of manipulator's end effector at each

\section{Trang 8}


point.

At each point on the interpolated curve, the Euler angles [9] can be obtained as follows.

$\left\{\begin{array}{l}\phi=\operatorname{atan} 2\left(a_{y}, a_{x}\right) \\ \theta=\operatorname{atan} 2\left(\sqrt{a_{x}^{2}+a_{y}^{2}}, a_{z}\right) \\ \psi=\operatorname{atan} 2\left(o_{z},-n_{z}\right)\end{array}\right.$

Substitute Eqs.(1) and (5 - 10) into Eq.(11), the angles $\phi, \theta, \psi$ can be calculated. Therefore, the inverse kinematics matrix of each point on the reference path is:

$$
\begin{aligned}
& {\left[\begin{array}{cc}
c_{\phi} c_{\theta} c_{\psi}-s_{\phi} s_{\psi} & -c_{\phi} c_{\theta} s_{\psi}-s_{\phi} c_{\psi} \\
s_{\phi} c_{\theta} c_{\psi}+c_{\phi} s_{\psi} & -s_{\phi} c_{\theta} s_{\psi}+c_{\phi} c_{\psi} \\
-s_{\theta} c_{\psi} & s_{\theta} s_{\psi} \\
0 & 0
\end{array}\right.} \\
& \left.\begin{array}{cc}
c_{\phi} s_{\theta} & X \\
s_{\phi} s_{\theta} & Y \\
c_{\theta} & Z \\
0 & 1
\end{array}\right]=\left[\begin{array}{cccc}
r_{11} & r_{12} & r_{13} & X \\
r_{21} & r_{22} & r_{2 a} & Y \\
r_{21} & r_{22} & r_{2 a} & Z \\
0 & 0 & 0 & 1
\end{array}\right]
\end{aligned}
$$

where,

$$
\begin{aligned}
& c_{\phi}=\cos \emptyset, c_{\theta}=\cos \theta, c_{\psi}=\cos \psi \\
& s_{\phi}=\sin \emptyset, s_{\theta}=\sin \theta, s_{\psi}=\sin \psi \\
& r_{11}=c_{\phi} c_{\theta} c_{\psi}-s_{\phi} s_{\psi} \\
& r_{12}=-c_{\phi} c_{\theta} s_{\psi}-s_{\phi} c_{\psi} \\
& r_{21}=s_{\phi} c_{\theta} c_{\psi}+c_{\phi} s_{\psi} \\
& r_{22}=-s_{\phi} c_{\theta} s_{\psi}+c_{\phi} c_{\psi} \\
& r_{a 1}=-s_{\theta} c_{\psi}, r_{22}=s_{\theta} s_{\psi} \\
& r_{13}=c_{\phi} s_{\theta}, r_{2 \mathrm{a}}=s_{\phi} s_{\theta}, r_{\mathrm{a}}=c_{\theta}
\end{aligned}
$$

$X_{s} Y_{v} Z$ is a position at $P_{i}:\left[\begin{array}{l}X \\ Y \\ Z\end{array}\right]=\left[\begin{array}{l}P_{i x} \\ P_{i y} \\ P_{i z}\end{array}\right]$

Thus, at each point $P_{i}$ on the interpolated curve, there is a set of angles $\phi_{\mathrm{i}}, \theta_{\mathrm{i}}, \psi_{\mathrm{i}}$ that satisfies Eq.(12). In a similar way, the interpolated curve is done with three-consecutive points on entirely reference path

\section{APPLY TO GLUE SHOE SOLE}

\subsection{Gluing path}

In this part, the proposed algorithm will be applied for 6-DOF manipulator to glue shoe sole. Assume, the curve of shoe sole (gluing path) (Fig.4) is divided into multipoint with isometric sampling distance.

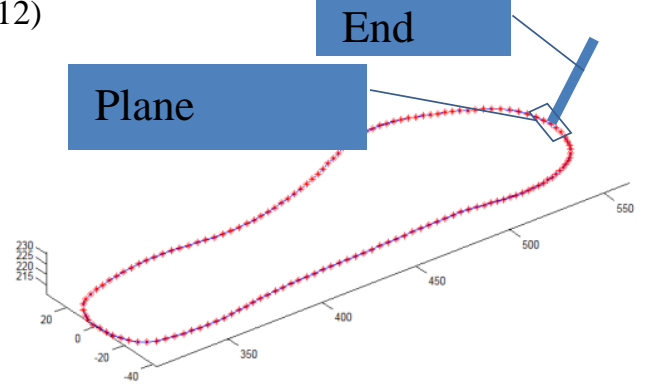

Figure 4. Gluing path

The sequence points of gluing path are available $P_{i}(i=1 \div 146)$. To glue shoe sole surface, the end effector has to move with constant velocity, and must be perpendicular to tangential plane at each point on sole surface. Using proposed algorithm for the 146 inverse kinematics matrices,

$$
\left[\begin{array}{cccc}
r_{11} & r_{12} & r_{12} & X \\
r_{21} & r_{22} & r_{2 \mathrm{a}} & Y \\
r_{21} & r_{\mathrm{2} 2} & r_{\mathrm{2a}} & Z \\
0 & 0 & 0 & 1
\end{array}\right]
$$


To correspond with the 146 points on entirely reference path

\subsection{Robot modeling}

Let $\mathrm{C}\left(x_{C}, y_{C}, z_{C}\right)$ and $P\left(X_{v}, Y_{v} Z\right)$ are the wrist point and the end effector's position of manipulator respectively. The wrist point [10] will be calculated as follows,

$$
\left[\begin{array}{l}
x_{C} \\
y_{C} \\
z_{C}
\end{array}\right]=\left[\begin{array}{l}
X-d_{7} r_{1 a} \\
Y-d_{7} r_{2 a} \\
Z-d_{7} r_{2 a}
\end{array}\right]
$$

From the manipulator configuration (Fig.6), the joint variables were obtained as follow,

$$
\begin{aligned}
& \theta_{1}=\arctan \left(\frac{y_{c}}{x_{c}}\right) \\
& r=\sqrt{x_{C}^{2}+y_{C}^{2}}
\end{aligned}
$$

where, $r$ is distance from $\mathrm{C}$ to origin $\mathrm{O}$ of $\left(0, \mathrm{X}_{0}, \mathrm{Y}_{0}\right)$ coordinate.

Apply the law of cosines $\Delta \mathrm{O}_{1} \mathrm{O}_{2} \mathrm{C}$ to obtain

$$
\cos \left(\angle O_{2} O_{1} C\right)=\frac{O_{1} O_{2}{ }^{2}+O_{1} C^{2}-O_{2} C^{2}}{2 . O_{1} O_{2} \cdot O_{1} C}=D
$$$$
\theta_{2}=\arctan \left(\frac{z_{C}-d_{1}}{r-a_{1}}\right)+\arctan \left(\frac{ \pm \sqrt{1-D^{2}}}{D}\right)
$$

$$
\cos \left(\angle x_{2} O_{2} C\right)=-\cos \left(\angle O_{1} O_{2} C\right)
$$$$
=\frac{O_{1} C^{2}-O_{1} O_{2}{ }^{2}-O_{2} C^{2}}{2 . O_{1} O_{2} \cdot O_{2} C}=E
$$

$$
\theta_{3}=\arctan \left(\frac{d_{4}}{a_{3}}\right)-\arctan \left(\frac{ \pm \sqrt{1-E^{2}}}{E}\right)
$$

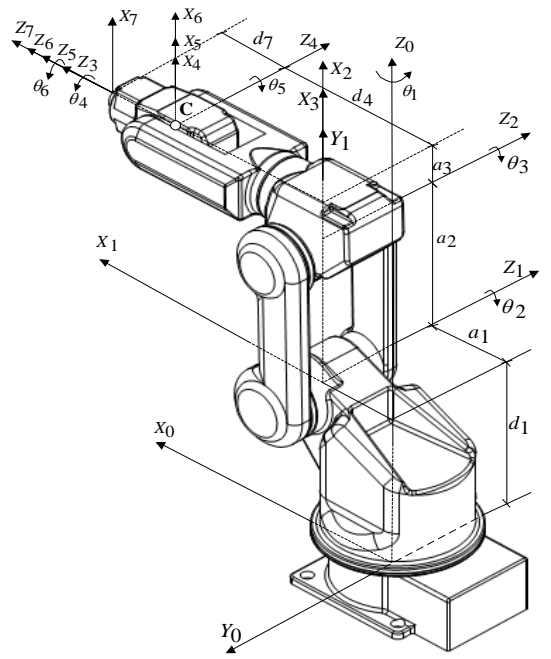

Figure 5. Frame of 6 DOF manipulator
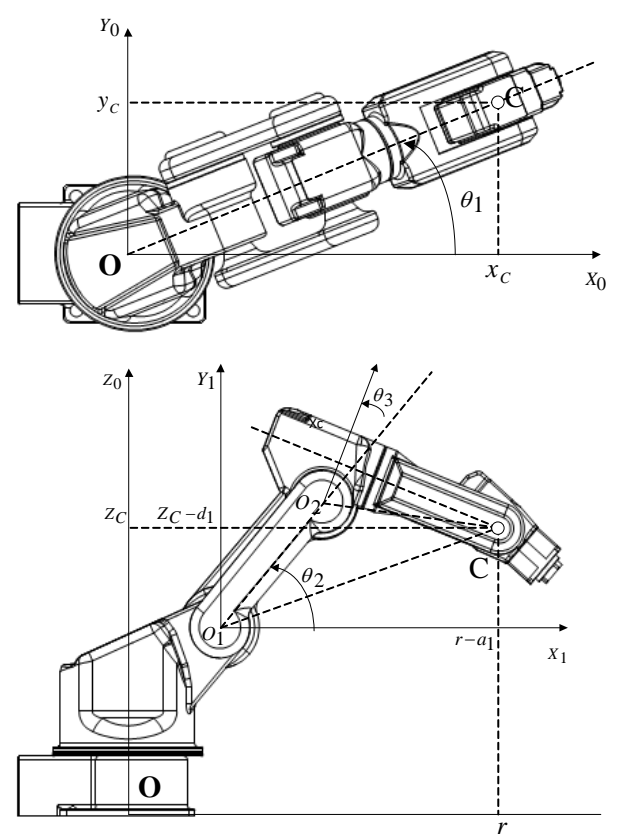

Figure 6. Manipulator configuration

where, $O_{1} C=\sqrt{\left(r-a_{1}\right)^{2}+\left(z_{C}-d_{1}\right)^{2}}$

$O_{2} C=\sqrt{a_{a}^{2}+d_{4}^{2}}, O_{1} O_{2}=a_{2}$ 
From Eq.(12) the end effector's orientation is calculated via wrist's orientation matrix [11]

$$
\begin{aligned}
& { }^{a} R_{6}=\left({ }^{0} R_{a}\right)^{T}{ }^{0} R_{6}= \\
= & {\left[\begin{array}{ccc}
c \theta_{1} c \theta_{2 a} & s \theta_{1} c \theta_{2 a} & s \theta_{2 a} \\
s \theta_{1} & -c \theta_{1} & 0 \\
c \theta_{1} s \theta_{2 a} & s \theta_{1} s \theta_{2 a} & -c \theta_{2 a}
\end{array}\right]\left[\begin{array}{lll}
r_{11} & r_{12} & r_{13} \\
r_{21} & r_{22} & r_{23} \\
r_{31} & r_{32} & r_{33}
\end{array}\right] } \\
= & {\left[\begin{array}{lll}
s_{11} & s_{12} & s_{1 a} \\
s_{21} & s_{22} & s_{2 a} \\
s_{11} & s_{22} & s_{2 a}
\end{array}\right] }
\end{aligned}
$$

where,

$$
\begin{aligned}
& c \theta_{1}=\cos \theta_{1}, c \theta_{2 a}=\cos \left(\theta_{2}+\theta_{a}\right) \\
& s \theta_{1}=\sin \theta_{1} s \theta_{2 a}=\sin \left(\theta_{2}+\theta_{a}\right) \\
& s_{1 a}=c \theta_{1} c \theta_{2 a} r_{1 a}+s \theta_{1} c \theta_{2 a} r_{2 a}+s \theta_{2 a} r_{a a} \\
& s_{2 a}=s \theta_{1} r_{1 a}-c \theta_{1} r_{2 a} \\
& s_{a a}=c \theta_{1} s \theta_{2 a} r_{1 a}+s \theta_{1} s \theta_{2 a} r_{2 a}-c \theta_{2 a} r_{a a} \\
& s_{a 2}=c \theta_{1} s \theta_{2 a} r_{12}+s \theta_{1} s \theta_{2 a} r_{22}-c \theta_{2 a} r_{a 2} \\
& s_{a 1}=c \theta_{1} s \theta_{2 a} r_{11}+s \theta_{1} s \theta_{2 a} r_{21}-c \theta_{2 a} r_{a 1}
\end{aligned}
$$

Say in other words:

$$
{ }^{\mathrm{a}} R_{6}={ }^{\mathrm{a}} R_{4^{*}}{ }^{4} R_{5^{*}}{ }^{5} R_{6}
$$

From Eq.(16) and (17), $\theta_{4}, \theta_{5}, \theta_{6}$ can be calculated as follows,

$$
\left\{\begin{array}{c}
\theta_{4}=\arctan \left(\frac{s_{23}}{s_{13}}\right) \\
\theta_{5}=\arctan \frac{\left(\frac{s_{13}+s_{23}}{c \theta_{4}+s \theta_{4}}\right)}{s_{33}} \\
\theta_{6}=\arctan \left(\frac{s_{32}}{-s_{31}}\right)
\end{array}\right.
$$

where,

$$
\begin{aligned}
& \theta_{1}, \theta_{2}, \theta_{a}, \theta_{4}, \theta_{5}, \theta_{6} \text { are joint variables } \\
& c \theta_{4}=\cos \theta_{4,} \quad s \theta_{4}=\sin \theta_{4}
\end{aligned}
$$

\section{SIMULATION RESULT AND DISCUSSION}

In the traditional method of trajectory control, the manipulator's orientation is a given matrix. Manipulator will move on trajectory with constant orientation, for instance the final inverse kinematics matrix of trajectory as follows,

$$
R=\left[\begin{array}{rrrr}
1 & 0 & 0 & X \\
0 & 1 & 0 & Y \\
0 & 0 & -1 & Z \\
0 & 0 & 0 & 1
\end{array}\right]
$$

The orientation: $\left[\begin{array}{rrr}1 & 0 & 0 \\ 0 & 1 & 0 \\ 0 & 0 & -1\end{array}\right]$

The position: $\left[\begin{array}{l}X \\ Y \\ Z\end{array}\right]$

It is easy to realize that the orientation does not change when the end effector moves on trajectory. This method is only applied in cases the orientation of the end effector is neglected.

In the previous method of trajectory control, the reference path was divided to multi-line which the length is not equal. For instance, there is a curve, which is divided into 6 lines (Fig.7)

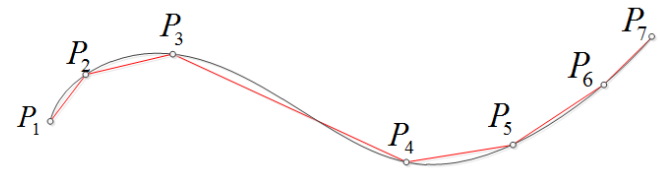

Figure 7. A curve is divided into 6 lines

At each line, there is a given matrix for manipulator's orientation

$R 1=\left[\begin{array}{rrrr}1 & 0 & 0 & X_{1} \\ 0 & 1 & 0 & Y_{1} \\ 0 & 0 & -1 & Z_{1} \\ 0 & 0 & 0 & 1\end{array}\right], \quad R 2=\left[\begin{array}{rrrr}1 & 0 & 0 & X_{2} \\ 0 & 1 & 0 & Y_{2} \\ 1 & 0 & -1 & Z_{2} \\ 0 & 0 & 0 & 1\end{array}\right]$.

$R 3=\left[\begin{array}{ccrc}1 & 0 & 1 & X_{\mathrm{a}} \\ 0 & 1 & 0 & Y_{\mathrm{a}} \\ 1 & 0 & -1 & Z_{\mathrm{a}} \\ 0 & 0 & 0 & 1\end{array}\right], \quad R 4=\left[\begin{array}{cccc}1 & 0 & 0 & X_{4} \\ 0 & 1 & 0 & Y_{4} \\ 0 & 0 & 1 & Z_{4} \\ 0 & 0 & 0 & 1\end{array}\right]$.

$R 5=\left[\begin{array}{ccrc}-1 & 0 & 1 & X_{5} \\ 0 & 1 & 0 & Y_{5} \\ 1 & 0 & -1 & Z_{5} \\ 0 & 0 & 0 & 1\end{array}\right], R 6=\left[\begin{array}{cccc}-1 & 0 & 0 & X_{6} \\ 0 & 1 & 0 & Y_{6} \\ 0 & 0 & 1 & Z_{6} \\ 0 & 0 & 0 & 1\end{array}\right]$ 
Where,

$$
\begin{aligned}
& \left(X_{1}, Y_{1}, Z_{1}\right) \in\left[P_{1} P_{2}\right],\left(X_{2}, Y_{2}, Z_{2}\right) \in\left[P_{2} P_{2}\right], \\
& \left(X_{1}, Y_{2}, Z_{9}\right) \in\left[P_{2} P_{4}\right],\left(X_{4}, Y_{4}, Z_{4}\right) \in\left[P_{4} P_{5}\right], \\
& \left(X_{5}, Y_{5}, Z_{5}\right) \in\left[P_{5} P_{6}\right],\left(X_{6}, Y_{6}, Z_{6}\right) \in\left[P_{6} P_{7}\right]
\end{aligned}
$$

This method is only applied in cases the orientation of the end effector is known in advance.

Inversely, the manipulator moves on trajectory with unknown varied orientations. So, the traditional methods cannot apply. Proposed method fully meets requirements about the position tracking and varied orientation. A reference path of shoe sole will be applied to simulate to prove the correction of the presented method. To verify the tracking performance of manipulator and gluing path of shoe sole, a PID controller was designed to simulate, the parameters of manipulator, reference path and PID are listed in Table 1.

\subsection{PID controller design for simulation}

The transfer function of PID controller with the filter is then

$$
\frac{U(s)}{E(s)}=\frac{K_{p}+K_{\mathrm{i}} / s+K_{d} s}{\tau_{f} s+1}=\frac{\frac{K_{d}}{\tau_{f}} s^{2}+\frac{K_{p}}{\tau_{f}} s+\frac{K_{\mathrm{i}}}{\tau_{f}}}{s^{2}+\frac{s}{\tau_{f}}}
$$

where a first - order filter is used.

E: Error

U: Controller

$K_{\mathrm{p},}, K_{\mathrm{f}}, K_{\mathrm{d}^{\mathrm{z}}}$ Proportional gain, Integral gain and derivative gain

$\tau_{f}:$ Time constant

A block diagram of PID controller with first - order filter is shown in Fig.8. A block diagram of control system is shown in Fig.9

$$
e=q_{-} r e f-q_{-} \text {feedback }
$$

$q_{-}$ref $=\left[\theta_{1}, \theta_{2}, \theta_{2}, \theta_{4}, \theta_{5}, \theta_{6}\right]$, and it was calculated by Eqs.(12 - 18). The results of simulation are presented in section 4.2

\subsection{Simulation result}

The results of simulation include position's tracking performance and orientation's tracking performance

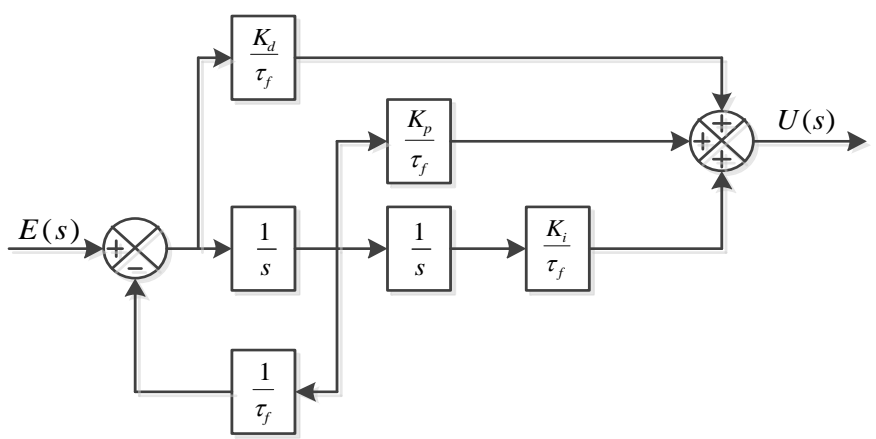

Figure 8. A block diagram of PID controller with first - order filter 
Table 1. Parameters of robot, reference path and PID

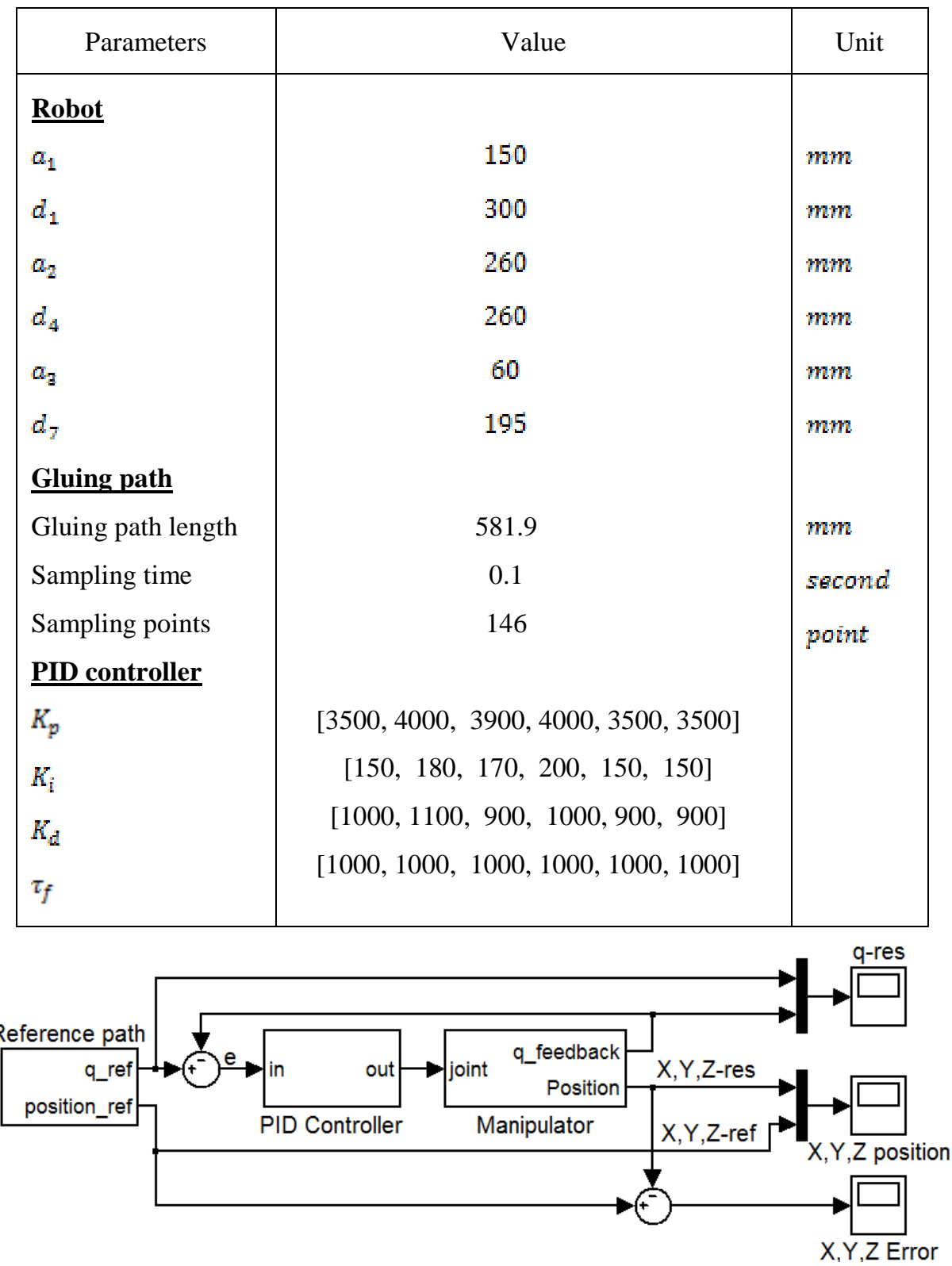

Figure 9. A block diagram of control system

\section{Position's tracking performance}

The simulation results are given in Fig.10 -

13 , the errors converge to zero after 0.88 seconds, the maximum error about $0.012 \mathrm{~mm}$. (Fig.13) 


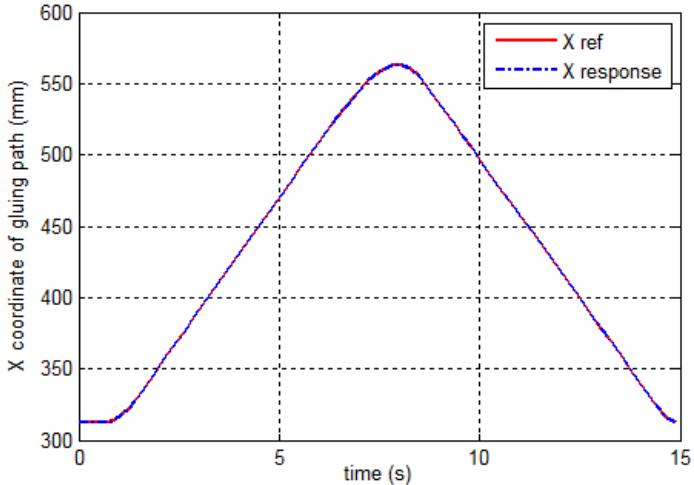

Figure 10. The tracking of $X$ coordinate

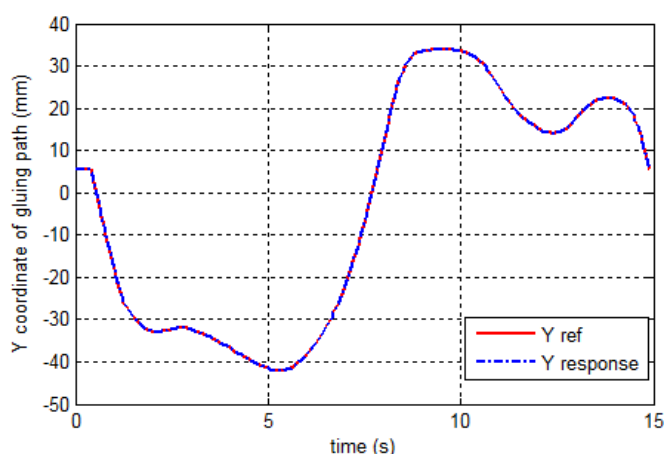

Figure 11. The tracking of $Y$ coordinate

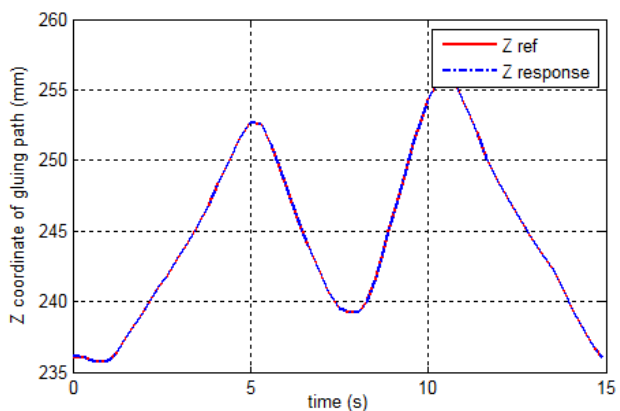

Figure 12. The tracking of $\mathrm{Z}$ coordinate

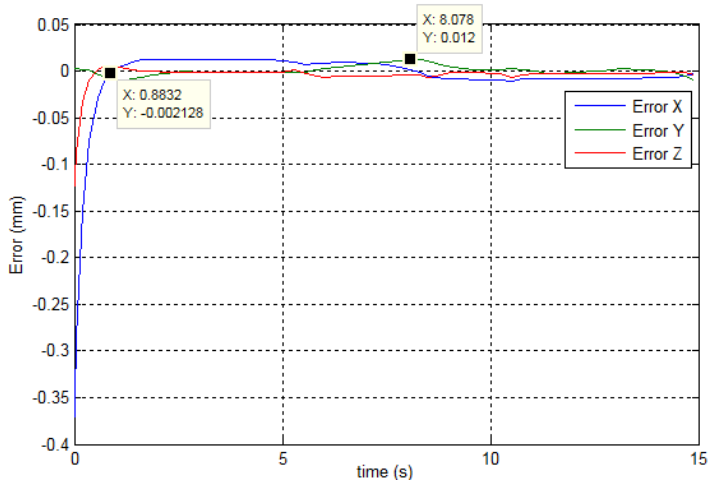

Figure13. The tracking errors of position

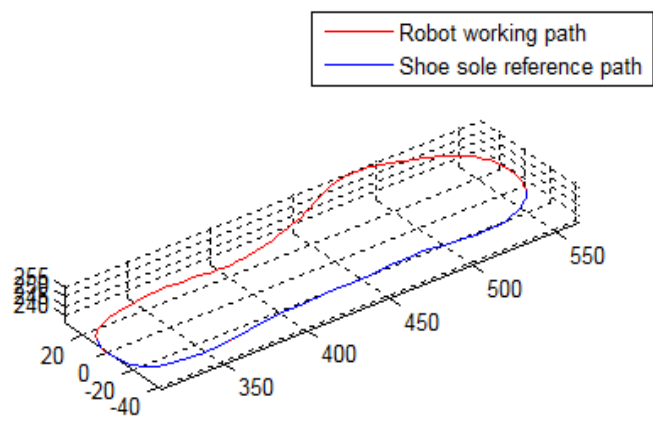

Figure 14. The tracking performance of position

\section{Orientation's tracking performance}

To glue shoe sole surface, the end effector has to move with constant velocity, and must be perpendicular to tangential plane at each point on sole surface. The results of simulation for tracking performance of orientation are given in Fig.15-16. As shown in Fig.15, the angular control closely track the reference angle (90 Degree). As shown in Fig.16, the maximum error is about 0.0088 degree. 


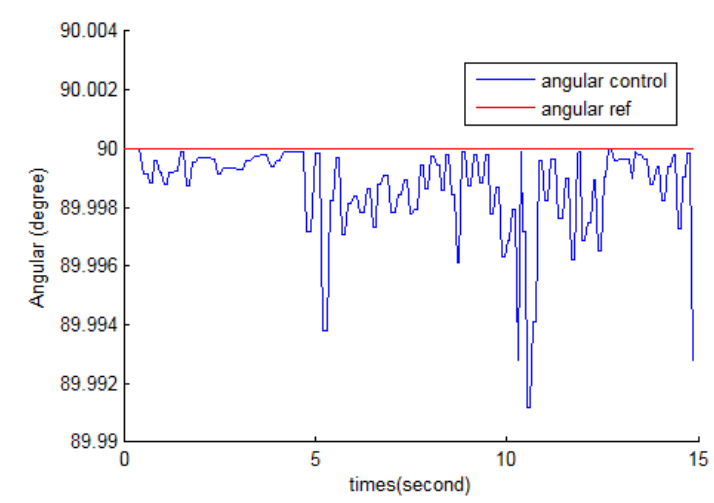

Figure 15. The tracking performance of orientation

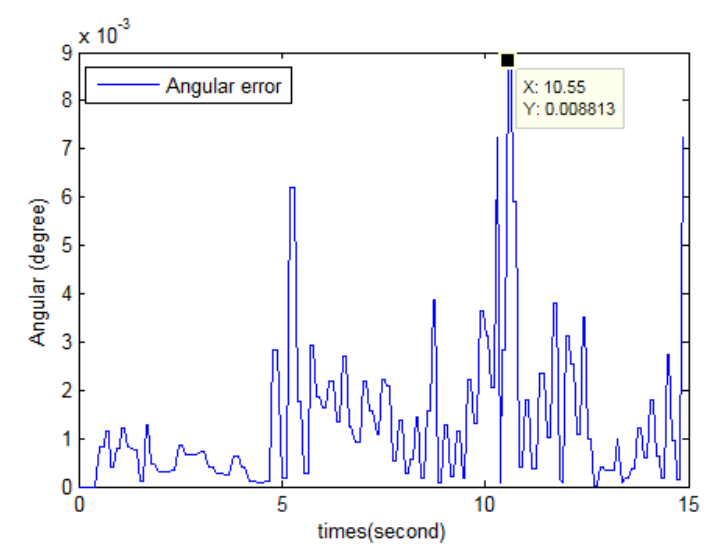

Figure16. The tracking error of orientation
From the simulation result, the manipulator can track arbitrary curve both position and varied orientation with acceptable error. So, the proposed algorithm can be used to calculate inverse kinematics matrix for manipulator from the reference curve.

\section{CONCLUSIONS}

This paper introduces an algorithm to obtain the inverse kinematics matrix of manipulator from the 3D curve based on Euler angles and interpolation. The good tracking performance of manipulator's end effector and reference path proved potential of algorithm.

\section{Thuật toán để đạt được ma trận động học từ đường cong $3 \mathrm{D}$ và ứng dụng vào bôi keo dán đế giày}

- Hà Lê Như Ngọc Thành

- Lư Thanh Tùng

- Nguyễn Tấn Tiến

Trường Đại học Bách Khoa, ĐHQG- HCM 


\section{TÓM TÁT:}

Ngày nay, robot được sủ dụng rộng rãi trong công nghiệp. Quỹ đạo chuyển động của robot ngày càng phức tạp hơn. Để robot có thể bám sát với quỹ đạo thi phải xác định được vị trí và huoóng của khâu công tác cuối cùng của robot. Bài báo trình bày một phuoong pháp xác định vị trí và huớng của khâu công tác cuối cùng của robot dụa vào đưòng quỹ đạo cho truớc. Phuong pháp này sẽ được úng dụng để bôi keo đế giày với một robot 6 bậc tụ do. Tù quỹ đạo cho trước là một đưòng cong bất kỳ, quỹ đạo này sẽ được chia thành nhiều điểm khác nhau. Sau đó, xác định véc to roll, pitch, yaw của khâu công tác cuối cùng của robot tại mỗi điểm đã chia. Cuối cùng, sủ dụng góc quay Euler và phưong pháp nội suy đưòng cong trong không gian $3 D$ để tính toán ma trận động học của robot tại mỗi điểm trên quỹ đạo cho truócc. Thêm vào đó, bài báo cũng đưa ra một ví du về đường bôi keo chi tiết giày để áp dụng kết quả tính toán. Để kiểm tra việc dò của co cấu chấp hành của robot khi dò theo đưòng cong cho trước, một bộ điều khiển PID được thiết kế để mô phỏng. Kết quả mô phỏng đã chưng minh tính đúng đắn của phuoong pháp đề xuất.

Tù khóa: ma trận động học, đường cong 3D, keo đế giày

\section{REFERENCES}

[1]. Raşit Köker, Hüseyin Ekiz, Raşit Köker, Hüseyin Ekiz, A study of neural network based inverse kinematics solution for a three-joint robot, Robotics and Autonomous Systems, Volume 49, Issues 3-4, Pages EX1-EX2, 135-258 (31 December 2004).

[2]. Wang, L.-C.T, A combined optimization method for solving the inverse kinematics problems of mechanical manipulator, Robotics and Automation, IEEE transactions on, Volume:7, Issue:4, Pages 489 - 499 (August 1991).

[3]. Thompson, Stuart E, Formulation of Joint Trajectories for Industrial Robots Using BSplines, Industrial Electronics, IEEE transactions, Volume: IE-34, Issue:2, Pages 192 - 199 (May, 1987).

[4]. Chi-Haur Wu, Planning and control of robot orientational path, System, Man and Cybernetics, IEEE transactions, Volume:
19, issue:5, pages $1234-1241$ (Sep/Oct 1989).

[5]. J. Angeles, A.Rojas, C.S.Lopez-Cajun, Trajectory planning in robotic continuouspath application, IEEE Journal on Robotics and Automation, Volume: 4, Issue: 4, Pages 380 - 385 .

[6]. Rafael renan Pacheco, Smooth Trajectory Tracking Interpolation on a Robot Simulator, EEE Latin American Robotics Symposium and Intelligent Robotics Meeting (1/2010).

[7]. Horsch T., Juttler B., Cartesian spline interpolation for industrial robots, Computer - Aided Design, 30, (3), Pages $217-224$ (1998)

[8]. S.D.Voliotics, Orientation planning in continuous path applications for wrist partitioned manipulator, Volume 139, 
issue: 6, pages 495 - 502, (1992).

[9]. Bruno Siciliano, Lorenzo Sciavicco, LuigiVillani, Giuseppe Oriolo, Robotics Modelling, Planning and Control, (2.19) of article 2.4.1, page 50, textbook Springer.

[10]. Mark W. Spong, Seth Hutchinson, M. Vidyasagar, Robot Modeling Planning and Control, (3.41) of article 3.3.2, page 88, textbook.
[11]. Reze N.Jazar, Theory of Applied Robotics, (6.6) of article 6.1, page 327, second edition, textbook Springer. 